\title{
PRINCÍPIOS ORIENTADORES DA INTEGRAÇÃO DAS TECNOLOGIAS DIGITAIS AO PROJETO POLÍTICO-PEDAGÓGICO
}

\author{
PRINCÍPIOS ORIENTADORES DE LA INTEGRACIÓN DE LAS TECNOLOGÍAS \\ DIGITALES AL PROYECTO POLÍTICO-PEDAGÓGICO
}

\section{PRINCIPLES GUIDING THE INTEGRATION OF DIGITAL TECHNOLOGIES TO THE POLITICAL-PEDAGOGICAL PROJECT}

\author{
Dilmeire Sant'Anna Ramos VOSGERAU ${ }^{1}$ \\ Marilusa ROSSARI ${ }^{2}$
}

RESUMO: O Projeto Político-Pedagógico (PPP) constitui-se como um documento resultante do diálogo entre os diversos segmentos da comunidade escolar, tendo por finalidade nortear as ações escolares. Espera-se, portanto, que a integração das tecnologias digitais seja antecipada nestas ações. Esta pesquisa tem como objetivo analisar as ações previstas sobre as tecnologias nos PPP, considerando os princípios para sua concepção elencados por Veiga $(1991,1998)$. Foram analisados PPP de cinco unidades educacionais de educação básica. Observou-se que as tecnologias digitais estão presentes na estrutura dos PPP, porém não apresentam uma organização que oriente para um posicionamento articulado aos princípios orientadores e o uso das tecnologias digitais.

PALAVRAS-CHAVE: Projeto político-pedagógico. Tecnologias digitais. Educação básica.

RESUMEN: El Proyecto Político-Pedagógico (PPP) se constituí como un documento resultante del diálogo entre los varios segmentos de la comunidad escolar, teniendo en cuenta orientar las acciones de la escuela. Por lo tanto se espera que la integración de las tecnologías digitales sea adelantada en estas acciones. Esta investigación tiene por objetivo analizar las acciones programadas sobre las tecnologías en los PPP, considerándose los principios para su concepción contemplados por Veiga (1991, 1998). Fueron analizados PPP de cinco unidades educacionales de Educación Básica. Se observó que las tecnologías digitales se encuentran en la estructura de los PPP, sin embargo no presentan una organización que guíe para una posición articulada a los principios orientadores y el uso de las tecnologías digitales.

PALAVRAS CLAVE: Proyecto político-pedagógico. Tecnologías digitales. Educación básica.

ABSTRACT: The Politic - Pedagogical Project (PPP) is a document that is a result from the dialogue among several segments of scholar community, which has the goal to

${ }^{1}$ Programa de Pós-Graduação em Educação. Pontifícia Universidade Católica do Paraná, Curitiba,

Paraná, Brasil. E-mail: dilmeire.vosgerau@ pucpr.br.

2 Programa de Pós-Graduação em Educação. Pontifícia Universidade Católica do Paraná, Curitiba, Paraná, Brasil. E-mail: mrossari@ solmarista.org.br. 
direct school actions. It is expected that the integration of digital technologies is anticipated in these actions. The aim of this research is to analyse previewed actions about technologies in PPP considering the principles for its conception engered by Veiga (1991, 1998). The PPP of five basic education units were analysed. It was observed that digital technoligies are present in PPP's structure, but do not show enough organization to direct an articulated positioning to guiding principles and the use of digital technologies.

KEYWORDS: Politic pedagogical project. Digital technologies. K-12 education.

\section{Introdução}

As discussões sobre o Projeto Político-Pedagógico (PPP) na educação brasileira iniciaram-se oficialmente na década de 1990, a partir da necessidade de desenvolvimento de um processo que oferecesse sustentação à autonomia administrativa, financeira e pedagógica das escolas. Esses debates culminaram com a inserção dessa temática na Lei de Diretrizes e Bases da Educação Nacional - LDBEN (BRASIL, 1996), atendendo ao mesmo tempo às intenções do discurso oficial e aos anseios dos trabalhadores docentes.

A LDBEN, em seus artigos 12, inciso I, 13, inciso I, e 14, incisos I e II (BRASIL, 1996), estabelece orientação legal de confiar à escola a responsabilidade por elaborar, executar e avaliar seu projeto pedagógico. Ademais, a legislação define normas de gestão democrática do ensino público na educação básica, de acordo com suas peculiaridades e conforme os seguintes princípios estabelecidos pelo art. 14 que define a participação dos profissionais da educação e da comunidade escolar.

Assim, a partir dessa lei, o Projeto Político-Pedagógico passou a ser um documento juridicamente reconhecido, que norteia as atividades desenvolvidas no espaço escolar e tem como objetivo central identificar e propor alternativas para melhorar a qualidade do ensino e a organização do trabalho pedagógico.

Contudo, novos desafios e exigências são apresentados à escola diariamente; como consequência, torna-se imprescindível que a revisão do Projeto PolíticoPedagógico seja um processo contínuo, para que sejam realizados ajustes e mudanças de acordo com os desafios e necessidades cotidianos. Integrar as tecnologias digitais ao contexto escolar é um desses desafios, sendo necessário, para isso, repensar práticas pedagógicas e de gestão, pois a utilização dos recursos tecnológicos só possui sentido ao contribuir para a melhoria da qualidade do ensino. 
É fato que a simples presença das tecnologias na escola não é, por si só, garantia de maior qualidade na educação (GATTI, 1993). Todavia, é inegável a necessidade de saber utilizar essas tecnologias para a busca e a seleção de informações que possam permitir a resolução de problemas do cotidiano, a compreensão do mundo e atuação na transformação de seu contexto (ALMEIDA, 2005). Considerando, então, os desafios e possibilidades trazidos pelas tecnologias e a necessidade de alinhamento das propostas de sua integração com os princípios, metas e propostas definidos nos Projetos PolíticosPedagógicos da escola, propomos, neste artigo, analisar as ações previstas sobre as tecnologias digitais nos PPP, considerando os princípios para sua concepção, elencados por Veiga (1991).

\section{A Construção do Projeto Político-Pedagógico}

Os princípios orientadores (Figura 1) na construção do projeto políticopedagógico descritos por Veiga (1991) partem dos ideais de liberdade e de solidariedade humana, que têm por finalidade o pleno desenvolvimento do educando, bem como sua qualificação para o trabalho, conforme abordado na LDBEN em seu artigo 3o. (BRASIL, 1996) ao elencar, entre outros aspectos, aqueles que garantam o acesso e permanência na escola, liberdade educacional, valorização do profissional da educação, gestão democrática, garantia de qualidade.

Figura 1: Descrição dos princípios orientadores na construção do PPP

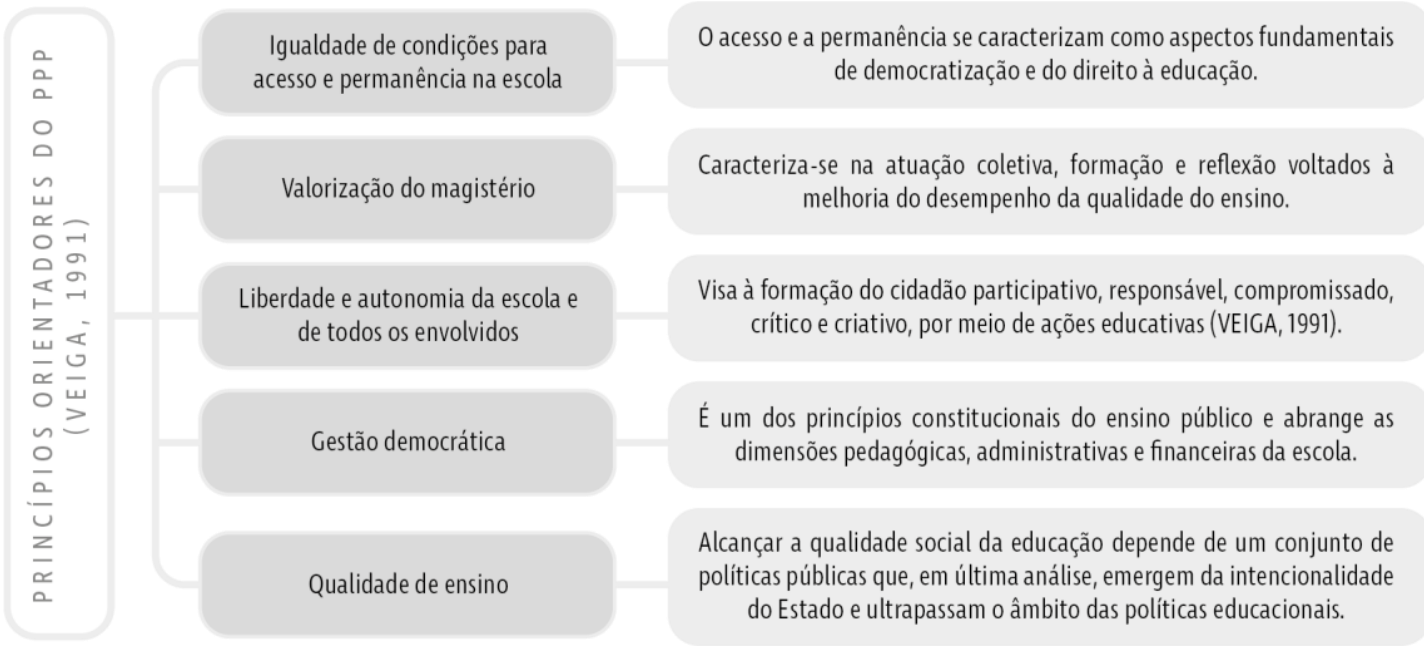

Fonte: elaboração própria a partir de Veiga (1991). 
Os princípios orientadores tornam-se fundamentais à organização dos processos educacionais pertinentes a escola, quando "garante[m] sua operacionalização nas estruturas escolares, pois uma coisa é estar no papel, na legislação, na proposta, no currículo, e outra é estar ocorrendo na dinâmica interna da escola, no real, no concreto" (VEIGA, 1991, p. 82).

Portanto, independente de qual seja a estrutura do projeto pedagógico (Figura 2), este deve explicitar em algum dos elementos de sua estrutura as ações e propostas escolares que deem suporte aos princípios definidos por Veiga (1991), promovendo a expansão e permanência dos educandos na escola com qualidade.

Figura 2: Elementos constitutivos do PPP sugeridos por Padilha (2005, p.90-93),

Vasconcelos (1995, p. 63), Veiga (1998, p. 26-27), Gandin (1999, p. 27-28)

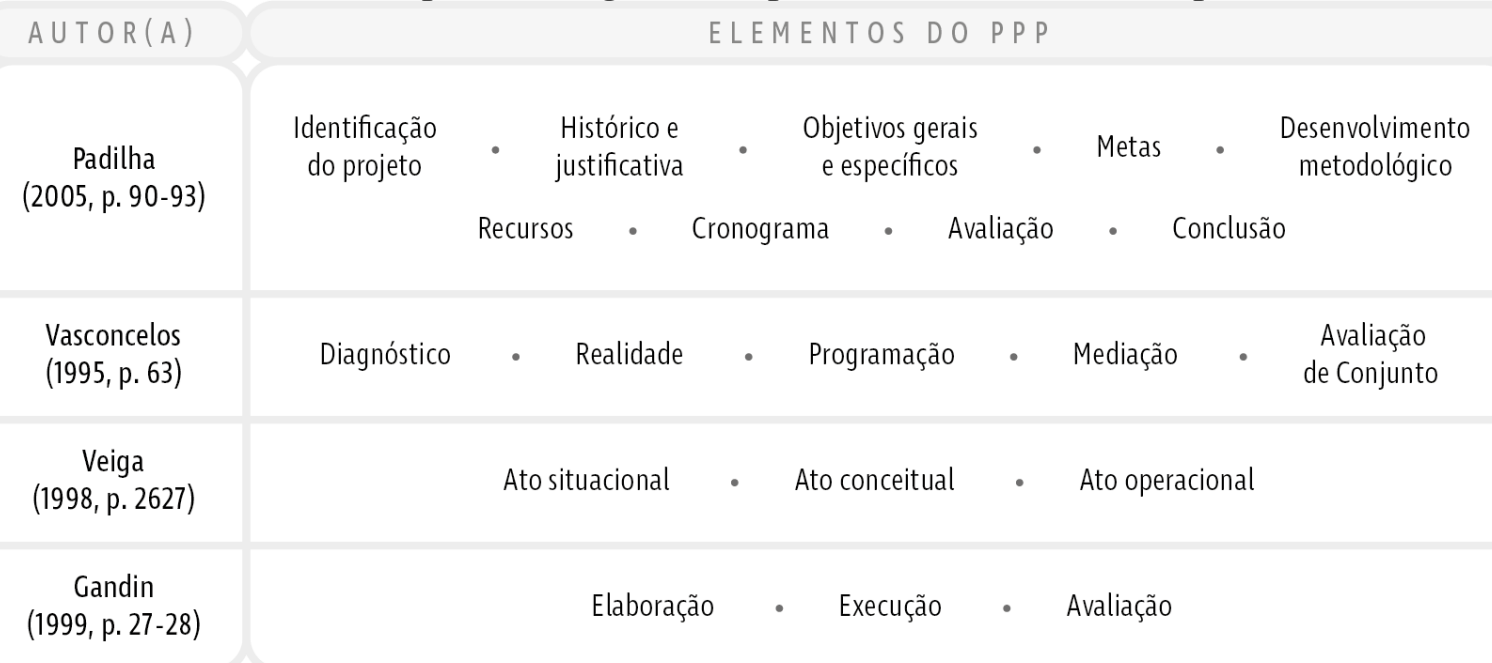

Fonte: Rossari e Vosgerau (2016, p. 44-45)

Quando a tecnologia passa a compor o espaço escolar, para sua integração é necessário promover a articulação aos princípios que orientam essa construção (Figura $3)$. 
Figura 3: Representação da articulação dos princípios orientadores do PPP com a tecnologia

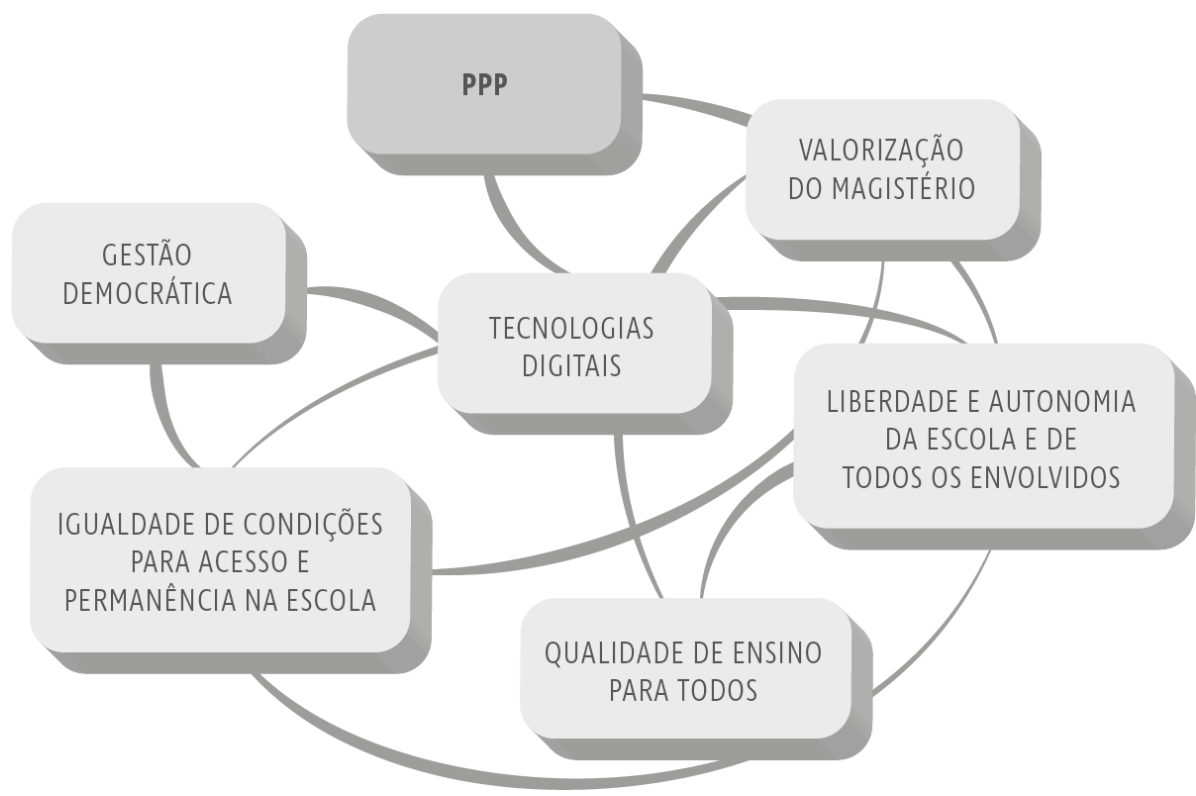

Fonte: elaboração própria a partir dos princípios de Veiga (1991).

Articulado aos princípios, o PPP torna-se um documento norteador de um processo de reflexão-ação na escola, e incorporando as tecnologias nas estruturas e na concepção de projeto educativo, torna-se um importante documento orientador da prática educativa da escola.

Essa proposta articulada entre PPP, tecnologias digitais e princípios orientadores potencializa a organização pedagógica e administrativa da escola, qualificando o processo de ensino e de aprendizagem.

\section{O PPP e a Integração das Tecnologias Digitais}

Ainda que o acesso às novas tecnologias digitais nas escolas tenha aumentado significativamente nos últimos anos, sua adoção não se observou de forma tão rápida e intensiva. As trajetórias ainda divergem e as tecnologias digitais e o currículo ainda são tratados de maneira desintegrada (ALMEIDA; VALENTE, 2011), embora apresentem facilidades que podem auxiliar o desenvolvimento de atividades curriculares, como som, imagem, animação e acesso à informação (ALMEIDA; VALENTE, 2011).

Esta integração decorre da formação de professores, que por sua vez perpassa a valorização do magistério, que é um dos princípios enunciados para a composição do 
PPP (VEIGA, 1991). No entanto, os cursos de formação de professores, muitas vezes, concentram-se nos aspectos tecnológicos, e pesquisas demonstram (SIMÕES, 2002; SILVA, 2009; ALMEIDA; VALENTE, 2011) que o domínio técnico e pedagógico não deve acontecer separadamente um do outro, pois isto dificulta as novas formas de organização do tempo e espaço das aulas e, conforme comprovado pela pesquisa de Simões (2002), a maior parte dos professores esboça definições de caráter estritamente técnico-instrumental e visões utilitaristas a respeito da tecnologia digital.

A utilização e a integração das tecnologias digitais na escola potencializam os processos de ensino e aprendizagem, entretanto, ainda falta a preparação da comunidade escolar para olhá-las como instrumento pedagógico, em utilizá-las com fins e objetivos definidos e educativos. A formação continuada, por sua vez, é um dos caminhos que proporcionam a discussão de como as tecnologias digitais podem ser usadas como instrumento à educação e à formação de profissionais da educação. (FIGUEIREDO; MERCADO, 2011)

Há alguns anos, a maior dificuldade para a inserção das tecnologias digitais nas instituições dizia respeito aos recursos (VOSGERAU, 2005); hoje, os recursos necessários não são mais o principal problema e, sim, a integração ao planejamento dos professores. Portanto, as mudanças tão esperadas com a chegada das tecnologias digitais não ocorreram como esperado. As instituições escolares passam, agora, pelo grande desafio de integrar e apropriar coerentemente as tecnologias digitais ao conteúdo previsto no currículo.

\section{Encaminhamento Metodológico}

Este estudo é de caráter qualitativo, sendo utilizados os pressupostos da pesquisa exploratória de Piovezan e Temporini (2005), por favorecerem a demonstração da variedade de perspectivas sobre o objeto a ser pesquisado.

O universo desta pesquisa consta de cinco Projetos Políticos-Pedagógicos de uma rede social de educação básica confessional, conforme caracterizado na Figura 4. 
Figura 4: Caracterização do universo da pesquisa

\begin{tabular}{|c|c|c|c|c|c|}
\hline & UNIDADE 1 & UNIDADE 2 & UNIDADE 3 & UNIDADE 4 & UNIDADE 5 \\
\hline ATENDIMENTO & $\begin{array}{l}\text { Educação infantil - } \\
\text { pré-escola I e II-, } \\
\text { ensino fundamental } \\
\text { do } 1^{\circ} \text { ao } 5^{\circ} \text { ano e } \\
\text { serviço de apoio } \\
\text { socioeducativo }\end{array}$ & $\begin{array}{l}6^{0} \text { a } 9^{\circ} \text { ano do } \\
\text { ensino fundamental } \\
\text { em tempo integral }\end{array}$ & $\begin{array}{l}\text { Ensino fundamental } \\
\text { | e ll e educação } \\
\text { infantil }\end{array}$ & $\begin{array}{l}1^{\circ} \text { ao } 5^{\circ} \text { ano do } \\
\text { ensino fundamental I } \\
\text { e } 6^{\circ} \text { ao } 9^{\circ} \text { ano do } \\
\text { ensino fundamental } \\
\|\end{array}$ & $\begin{array}{l}\text { Ensino fundamental } \\
\text { I, apoio } \\
\text { socioeducativo e } \\
\text { aprendizagem } \\
\text { profissional }\end{array}$ \\
\hline $\begin{array}{l}N^{\circ} \text { DE EDUCANDOS } \\
\text { ATENDIDOS }\end{array}$ & Não consta & 315 & 514 & 890 & 452 \\
\hline PROFISSIONAIS & Não consta & 15 professores & 26 professores & 29 professores & 15 professores \\
\hline N DE PÁGINAS PPP & 75 & 114 & 301 & 131 & 245 \\
\hline
\end{tabular}

Fonte: elaboração própria.

\section{A Integração nas Tecnologias nos Projetos Políticos-Pedagógicos}

A partir dos dados levantados pela pesquisa, observa-se (Figura 5) que todos os Projetos Políticos-Pedagógicos consideram a tecnologia digital em um ou mais elementos que constituem, na visão de Padilha (2005), a estrutura do documento. Os documentos organizam a ação escolar e estabelecem princípios orientadores, diretrizes e propostas de ação para melhor organizar, sistematizar e significar as atividades educativas, construindo práticas pedagógicas inovadoras que envolvam professores e estudantes nos processos de ensino e aprendizagem.

Figura 5: Presença de elementos no PPP que informam sobre a integração das tecnologias digitais

\begin{tabular}{|c|c|c|c|c|c|}
\hline ELEMENTOS DO PPP (PADILHA, 2005) & PPP 1 & PPP 2 & PPP 3 & PPP 4 & PPP 5 \\
\hline Identificação do projeto & & - & & - & \\
\hline Histórico e justificativa & & ○ & ○ & & ○ \\
\hline Objetivos gerais e específicos & ○ & ○ & ○ & ○ & 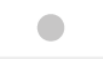 \\
\hline Metas & ○ & ○ & ○ & & \\
\hline Desenvolvimento metodológico & ○ & ○ & ○ & ○ & O \\
\hline Recursos & & ○ & ○ & ○ & O \\
\hline Cronograma & & ○ & & & - \\
\hline Avaliação & ○ & ○ & ○ & & O \\
\hline Conclusão & & ○ & & & \\
\hline
\end{tabular}

Fonte: elaboração própria.

RIAEE - Revista Ibero-Americana de Estudos em Educação, v. 12, n. 2, p. 1020-1036, $2017 . \quad$ E-ISSN: 1982-5587 
Nos dados referentes à identificação da escola (Figura 6), observa-se que dois PPP mencionam informações distintas, mas complementares, sobre a tecnologia digital: função da escola frente às tecnologias digitais (PPP02), a finalidade da tecnologia digital para a escola (PPP04).

Figura 6: Presença da tecnologia digital na identificação da escola

\begin{tabular}{|c|c|c|c|}
\hline PPP & EXTRATOS DO PPP & INDICADORES & $\begin{array}{c}\text { FUNÇÕES } \\
\text { DESEMPENHADAS }\end{array}$ \\
\hline PPP 2 & $\begin{array}{l}\text { A liberdade de expressão, o pluralismo dos meios de comunicação, o multilinguís- } \\
\text { simo, a igualdade de acesso às expressões artísticas, ao conhecimento científico e } \\
\text { tecnológico - inclusive em formato digital - e a possibilidade, para todas as } \\
\text { culturas, de estar presentes nos meios de expressão e de difusão, são garantias da } \\
\text { diversidade sociocultural. }\end{array}$ & $\begin{array}{c}\text { Escola como espaço } \\
\text { de inclusão digital }\end{array}$ & $\begin{array}{l}\text { Função da escola } \\
\text { frente à tecnologia }\end{array}$ \\
\hline & $\begin{array}{l}\text { A sociedade da informação tem que ser para todos. Sua democratização deve } \\
\text { possibilitar que toda a população tenha acesso às novas tecnologias, } \\
\text { utilizando-as em todo o seu potencial, incluindo o acesso à rede mundial. }\end{array}$ & \multirow{2}{*}{$\begin{array}{l}\text { A tecnologia como } \\
\text { propulsora da } \\
\text { produção e } \\
\text { disseminação do } \\
\text { conhecimento }\end{array}$} & \multirow{2}{*}{$\begin{array}{l}\text { Finalidade da } \\
\text { tecnologia para } \\
\text { escola }\end{array}$} \\
\hline PPP 4 & $\begin{array}{l}\text { Face à globalização, aos avanços tecnológicos, às descobertas científicas, às } \\
\text { influências dos meios de comunicação social e às rápidas mudanças que vêm } \\
\text { ocorrendo no âmbito cultural, social, político, econômico e educacional, faz-se } \\
\text { necessário que os estabelecimentos de ensino não fiquem estagnados, sem uma } \\
\text { reflexão acerca do seu papel, da sua organização, dos seus princípios. }\end{array}$ & & \\
\hline
\end{tabular}

Fonte: elaboração própria.

No tópico dedicado ao histórico da escola e justificativa das suas concepções educacionais foram encontradas menção às tecnologias digitais em três PPP (Figura 7), focando: a função da escola na inclusão digital, compromissos do cidadão nesta sociedade tecnológica e a função da escola na alfabetização digital e o uso pedagógico da tecnologia digital. 
Figura 7: Presença da Tecnologia digital no histórico e na justificativa do PPP

\begin{tabular}{|c|c|c|c|}
\hline PPP & EXTRATOS DO PPP & INDICADORES & $\begin{array}{c}\text { FUNÇÕES } \\
\text { DESEMPENHADAS }\end{array}$ \\
\hline PPP 2 & $\begin{array}{l}\text { Os educandos da Unidade em sua maioria não têm computador em casa ou } \\
\text { acesso aos recursos digitais. Com as Oficinas de Informática promovidas pela } \\
\text { Unidade, os educandos participam da inclusão digital através de Projetos de } \\
\text { Trabalho como alavanca para o desenvolvimento social autossustentável e } \\
\text { promoção de cidadania. }\end{array}$ & Inclusão digital & $\begin{array}{l}\text { Função da escola } \\
\text { frente à tecnologia }\end{array}$ \\
\hline PPP 3 & $\begin{array}{l}\text { Formamos uma sociedade com avanços tecnológicos com grandes conquistas. } \\
\text { Diante dessa realidade, a nossa missão é construir um cidadão crítico, participati- } \\
\text { vo, conhecedor de seus direitos e responsabilidades, transformador, envolvendo- } \\
\text {-se plenamente e solidariamente com a sociedade que o cerca, um homem } \\
\text { consciente na preservação na natureza. Enfim, um ser fraterno e solidário. }\end{array}$ & $\begin{array}{l}\text { Compromissos do } \\
\text { cidadão nesta } \\
\text { sociedade } \\
\text { tecnológica }\end{array}$ & $\begin{array}{l}\text { Articulação entre a } \\
\text { formação e } \\
\text { tecnologia }\end{array}$ \\
\hline \multirow{3}{*}{ PPP 5} & $\begin{array}{l}\text { No mundo globalizado em que vivemos e com avanços tecnológicos diários, não } \\
\text { podemos desconsiderar a necessidade do acesso à informática e ao conhecimento } \\
\text { tecnológico. }\end{array}$ & Inclusão digital & $\begin{array}{l}\text { Função da escola } \\
\text { frente à tecnologia }\end{array}$ \\
\hline & $\begin{array}{l}\text { No Brasil aumenta o descompasso na exigência da alfabetização. Antes, eram } \\
\text { consideradas alfabetizadas aquelas pessoas que sabiam ler e escrever o básico. Os } \\
\text { analfabetos dos novos tempos serão aqueles incapazes de manusear um } \\
\text { computador. }\end{array}$ & $\begin{array}{c}\text { Alfabetização } \\
\text { digital }\end{array}$ & $\begin{array}{l}\text { Função da escola } \\
\text { frente à tecnologia }\end{array}$ \\
\hline & $\begin{array}{l}\text { A tecnologia sempre auxiliou o homem em suas tarefas, seja com a enxada ou } \\
\text { com o computador. Assim, sem perder de vista, é evidente, os pressupostos } \\
\text { filosóficos Maristas, almejamos oferecer mais um subsídio para que os educandos } \\
\text { possam construir seus conhecimentos. }\end{array}$ & $\begin{array}{l}\text { Uso pedagógico da } \\
\text { tecnologia }\end{array}$ & $\begin{array}{l}\text { Finalidade da } \\
\text { tecnologia para } \\
\text { escola }\end{array}$ \\
\hline
\end{tabular}

Fonte: elaboração própria.

Na apresentação dos objetivos gerais e específicos da escola, foram encontradas menção às tecnologias em três documentos (Figura 8) 
Figura 8: Presença da Tecnologia digital nos objetivos gerais e específicos

\begin{tabular}{|c|c|c|c|}
\hline PPP & EXTRATOS DO PPP & INDICADORES & $\begin{array}{l}\text { FUNÇÕES } \\
\text { DESEMPENHADAS }\end{array}$ \\
\hline \multirow[b]{2}{*}{ PPP 1} & $\begin{array}{l}\text { Promover situações relacionais em que o educando desenvolva o senso de } \\
\text { coletividade, para atuar e colocar a serviço da comunidade os domínios cultural, } \\
\text { espiritual, ético, científico e tecnológico construídos. }\end{array}$ & Inclusão digital & $\begin{array}{l}\text { Função da escola } \\
\text { frente à tecnologia }\end{array}$ \\
\hline & $\begin{array}{l}\text { Construir e aplicar conceitos das várias áreas do conhecimento para a compreen- } \\
\text { são de fenômenos naturais, de processos histórico-geográficos, da produção } \\
\text { tecnológica e das manifestações artísticas. }\end{array}$ & $\begin{array}{l}\text { A tecnologia } \\
\text { propulsora da } \\
\text { produção e } \\
\text { disseminação do } \\
\text { conhecimento }\end{array}$ & $\begin{array}{l}\text { Finalidade da } \\
\text { tecnologia para } \\
\text { escola }\end{array}$ \\
\hline PPP 2 & Desenvolver habilidades de manipulação do software. & $\begin{array}{l}\text { Alfabetização } \\
\text { digital }\end{array}$ & $\begin{array}{l}\text { Função da escola } \\
\text { frente à tecnologia }\end{array}$ \\
\hline \multirow{3}{*}{ PPP 4} & $\begin{array}{l}\text { Educar para a democracia, integrando as práticas pedagógicas cotidianas, as } \\
\text { novas tecnologias e a pluralidade de linguagens que constitui o mundo. }\end{array}$ & $\begin{array}{l}\text { Uso pedagógico da } \\
\text { tecnologia }\end{array}$ & $\begin{array}{l}\text { Finalidade da } \\
\text { tecnologia para } \\
\text { escola }\end{array}$ \\
\hline & $\begin{array}{l}\text { Buscar a formação plena do educando e da comunidade educativa no âmbito do } \\
\text { conhecimento formal, da tecnologia, do letramento, das expressões artístico-cul- } \\
\text { turais, da leitura e produção críticas de mídias, audiovisuais. }\end{array}$ & Letramento digital & $\begin{array}{l}\text { Função da escola } \\
\text { frente à tecnologia }\end{array}$ \\
\hline & Assegurar a utilização dos instrumentos e dos sistemas: softwares específicos. & $\begin{array}{l}\text { Alfabetização } \\
\text { digital }\end{array}$ & $\begin{array}{l}\text { Função da escola } \\
\text { frente à tecnologia }\end{array}$ \\
\hline PPP 5 & $\begin{array}{l}\text { Compreender os fenômenos naturais, seu desenvolvimento por acumulação, } \\
\text { continuidade ou ruptura de paradigmas relacionando o avanço científico e } \\
\text { tecnológico às transformações da sociedade e do ambiente. }\end{array}$ & $\begin{array}{l}\text { Uso pedagógico da } \\
\text { tecnologia }\end{array}$ & $\begin{array}{l}\text { Finalidade da } \\
\text { tecnologia para } \\
\text { escola }\end{array}$ \\
\hline
\end{tabular}

Fonte: elaboração própria.

Foram encontradas em dois PPP metas relacionadas às tecnologias (Figura 9).

Figura 9: Presença da Tecnologia digital nas metas definidas para a escola

\begin{tabular}{|c|c|c|c|}
\hline PPP & EXTRATOS DO PPP & INDICADORES & $\begin{array}{l}\text { FUNÇÕES } \\
\text { DESEMPENHADAS }\end{array}$ \\
\hline PPP 2 & $\begin{array}{l}\text { Projetos pedagógicos temáticos interdisciplinares com a utilização de novas } \\
\text { tecnologias educacionais. }\end{array}$ & $\begin{array}{l}\text { Uso pedagógico da } \\
\text { tecnologia }\end{array}$ & $\begin{array}{c}\text { Finalidade da } \\
\text { tecnologia para } \\
\text { escola }\end{array}$ \\
\hline PPP 3 & $\begin{array}{l}\text { Criação de bibliotecas interativas, com novas tecnologias que ofereçam produtos } \\
\text { e serviços acrescidos de significado e que promovam ações culturais direcionadas } \\
\text { às comunidades, contribui para o desenvolvimento de valores humanos e de } \\
\text { cidadania, propiciando, entre outras coisas, a interação dos usuários com as } \\
\text { fontes de informação. }\end{array}$ & Inclusão digital & $\begin{array}{l}\text { Função da escola } \\
\text { frente à tecnologia }\end{array}$ \\
\hline
\end{tabular}

Fonte: elaboração própria.

Em todos os PPP analisados foram encontradas indicações metodológicas pontuais e de variados aspectos sobre o uso a ser feito da tecnologia digital na escola (Figura 10). 
Figura 10: Presença da tecnologia digital no desenvolvimento metodológico

\begin{tabular}{|c|c|c|c|}
\hline PPP & EXTRATOS DO PPP & INDICADORES & $\begin{array}{c}\text { FUNÇÕES } \\
\text { DESEMPENHADAS }\end{array}$ \\
\hline PPP 1 & $\begin{array}{l}\text { Somos cidadãos de uma nova sociedade do conhecimento, altamente tecnologi- } \\
\text { zada promovendo a ética, a justiça social, o meio ambiente e o respeito ao } \\
\text { indivíduo e às relações interpessoais. }\end{array}$ & Inclusão digital & $\begin{array}{l}\text { Função da escola } \\
\text { frente à tecnologia }\end{array}$ \\
\hline \multirow{2}{*}{ PPP 2} & $\begin{array}{l}\text { Computador como um meio didático. Ele apresenta facilidade para simular } \\
\text { fenômenos e animação, é uma ferramenta, um recurso que pode facilitar ou } \\
\text { dificultar o processo de ensino-aprendizagem. }\end{array}$ & \multirow{2}{*}{$\begin{array}{l}\text { Uso pedagógico da } \\
\text { tecnologia }\end{array}$} & \multirow{2}{*}{$\begin{array}{l}\text { Finalidade da } \\
\text { tecnologia para } \\
\text { escola }\end{array}$} \\
\hline & $\begin{array}{l}\text { Aulas assistidas com softwares educacionais que utilizam os recursos da multimí- } \\
\text { dia para a assimilação de conteúdos da grade curricular, ministradas no laborató- } \\
\text { rio de informática. }\end{array}$ & & \\
\hline PPP 3 & $\begin{array}{l}\text { Sala de informática, quadra poliesportiva coberta, refeitório, banheiros, ambien- } \\
\text { tes administrativos e gerenciais. Como infraestrutura material: cadeiras, mesas, } \\
\text { armários, estantes, computadores, quadros, recursos audiovisuais e demais } \\
\text { materiais pertinentes às atividades. }\end{array}$ & Infraestrutura & Garantir recursos \\
\hline \multirow{2}{*}{ PPP 4} & $\begin{array}{l}\text { Projeto de Informática Educativa coaduna com as teorias sociointeracionistas de } \\
\text { aprendizagem. A partir disso, e como uma das implicações metodológicas das } \\
\text { atividades pedagógicas que envolvem a Informática Educativa, desenvolve-se o } \\
\text { trabalho com as diferentes turmas/grupos preferencialmente na perspectiva de } \\
\text { projetos ou recurso complementar em aulas pontuais. }\end{array}$ & $\begin{array}{l}\text { Uso pedagógico da } \\
\text { tecnologia }\end{array}$ & $\begin{array}{l}\text { Finalidade da } \\
\text { tecnologia para } \\
\text { escola }\end{array}$ \\
\hline & $\begin{array}{l}\text { A Informática Educativa se constitui como uma linguagem que possibilita a } \\
\text { inter-relação entre as diferentes áreas do conhecimento e o acesso às TIC como } \\
\text { forma de apropriação, reconstrução e compartilhamento de saberes. }\end{array}$ & $\begin{array}{l}\text { A tecnologia } \\
\text { propulsora da } \\
\text { produção e } \\
\text { disseminação do } \\
\text { conhecimento }\end{array}$ & $\begin{array}{l}\text { Finalidade da } \\
\text { tecnologia para } \\
\text { escola }\end{array}$ \\
\hline \multirow{3}{*}{ PPP 5} & $\begin{array}{l}\text { As atividades desenvolvidas no laboratório de informática são variadas de acordo } \\
\text { com cada série, aprofundando e dando continuidade a conteúdos trabalhados em } \\
\text { sala de aula. }\end{array}$ & \multirow{3}{*}{$\begin{array}{l}\text { Uso pedagógico da } \\
\text { tecnologia }\end{array}$} & \multirow{3}{*}{$\begin{array}{l}\text { Finalidade da } \\
\text { tecnologia para } \\
\quad \text { escola }\end{array}$} \\
\hline & $\begin{array}{l}\text { Com o uso de recursos pedagógicos como a informática, elaboração, leitura e } \\
\text { interpretação de gráficos, utilização constante do laboratório de matemática } \\
\text { para jogos e aulas práticas, atividades concretas, visitas, projetos específicos de } \\
\text { cada série, é oportunizando ao aluno observar, analisar, comparar, criticar, } \\
\text { concluir e generalizar fatos que resultam na formação do seu saber. }\end{array}$ & & \\
\hline & $\begin{array}{l}\text { Atualmente, trabalhamos com as oficinas de Informática Educativa, Jogos } \\
\text { Cooperativos, Comunicação Comunitária e Artes Visuais, nas quais procuramos } \\
\text { desenvolver em nossos educandos a criatividade, a oralidade, a cooperação e as } \\
\text { relações interpessoais. }\end{array}$ & & \\
\hline
\end{tabular}

Fonte: elaboração própria.

Em todos os PPP encontra-se menção à presença de computadores na escola, sendo que em três deles o acesso e uso é no laboratório de informática (PPP01, PPP02 e PPP03) e em dois deles (PPP04 e PPP05) o local de acesso não é informado (Figura 11). 
Figura 11: Presença da indicação de tecnologias digitais nos recursos das unidades escolares

\begin{tabular}{|c|c|c|c|}
\hline PPP & EXTRATOS DO PPP & INDICADORES & $\begin{array}{l}\text { FUNÇÕES } \\
\text { DESEMPENHADAS }\end{array}$ \\
\hline PPP 1 & Laboratório de informática. & \multirow{7}{*}{ Infraestrutura } & \multirow{7}{*}{ Garantir recursos } \\
\hline PPP 2 & Laboratório de informática. & & \\
\hline PPP 3 & $\begin{array}{l}\text { Sala de recursos audiovisuais, sala de informática, computadores, recursos } \\
\text { audiovisuais. }\end{array}$ & & \\
\hline \multirow[b]{2}{*}{ PPP 4} & $\begin{array}{l}\text { Computadores com acesso à Internet por banda larga, ligados em rede, projetor } \\
\text { multimídia e tela interativa. }\end{array}$ & & \\
\hline & $\begin{array}{l}\text { Espaço para atendimento de pais e educandos com computador e internet. A sala } \\
\text { dos professores está equipada com mesa de trabalho, computadores e } \\
\text { escaninhos. Computadores/Monitores nos Laboratórios de Informática. }\end{array}$ & & \\
\hline \multirow[t]{2}{*}{ PPP 5} & $\begin{array}{l}\text { Aparelho de som, CDs, Televisor, Vídeo Cassete, Retroprojetor, Multimídia, DVDs e } \\
\text { Automóvel para eventuais passeios, materiais didáticos e esportivos, espaço físico } \\
\text { e lanche. }\end{array}$ & & \\
\hline & $\begin{array}{l}\text { Computadores, Programas, monitor de video e computador e computador com } \\
\text { teclado, pincel e quadro, bancadas para } 4 \text { computadores. }\end{array}$ & & \\
\hline
\end{tabular}

Fonte: elaboração própria.

Nos cronogramas dos PPP analisados a presença de indicadores sobre tecnologia digital aparece em dois (2) PPP de forma genérica, sem precisar efetivamente prazos ou datas para implementação das tecnologias digitais no âmbito escolar (Figura 12).

Figura 12: Presença de indicadores relacionados às tecnologias digitais nos cronogramas

\begin{tabular}{|c|c|c|c|}
\hline PPP & EXTRATOS DO PPP & INDICADORES & $\begin{array}{c}\text { FUNÇÕES } \\
\text { DESEMPENHADAS }\end{array}$ \\
\hline PPP 4 & Linguagem, códigos e suas tecnologias. & $\begin{array}{c}\text { Áreas de } \\
\text { conhecimento }\end{array}$ & \multirow{3}{*}{$\begin{array}{l}\text { Finalidade da } \\
\text { tecnologia para } \\
\text { escola }\end{array}$} \\
\hline \multirow{2}{*}{ PPP 5} & Ser Humano/Micro-organismos/Tecnologia. & $\begin{array}{c}\text { Áreas de } \\
\text { conhecimento }\end{array}$ & \\
\hline & $\begin{array}{l}\text { Aulas de Informática, destinados especificamente para } 0 \text { atendimento dos } \\
\text { educandos de Ensino Fundamental. }\end{array}$ & Uso pedagógico & \\
\hline
\end{tabular}

Fonte: elaboração própria.

Dois dos cinco PPP analisados incluem as tecnologias digitais em seu processo de avaliação, ora indicando o computador como método (PPP02), ora informando que podem ser utilizados softwares no processo de avaliação (PPP02) e incluindo a habilidade de manipulação de software, que corresponderia a um uso técnico (PPP02). 
Em outra situação (PPP05), é apenas informado que o Laboratório deve ser um espaço também considerado no processo de avaliação. (Figura 13).

Figura 13: Presença da tecnologia digital na definição do processo de avaliação

\begin{tabular}{|c|c|c|c|}
\hline PPP & EXTRATOS DO PPP & INDICADORES & $\begin{array}{c}\text { FUNÇÕES } \\
\text { DESEMPENHADAS }\end{array}$ \\
\hline \multirow{3}{*}{ PPP 2} & $\begin{array}{l}\text { Cabe ao educador considerar no contexto das práticas de avaliação encaminha- } \\
\text { mentos diversos como a observação, a intervenção, a revisão de noções e } \\
\text { subjetividades, isto é, buscar diversos métodos avaliativos (formas escritas, orais } \\
\text { e de demonstração), incluindo o uso de materiais manipuláveis, computador e/ou } \\
\text { calculadora. }\end{array}$ & \multirow[t]{2}{*}{ Uso pedagógico } & \multirow{5}{*}{$\begin{array}{l}\text { Finalidade da } \\
\text { tecnologia para } \\
\quad \text { escola }\end{array}$} \\
\hline & $\begin{array}{l}\text { O registro do processo que será realizado diariamente em um caderno, através de } \\
\text { fotos, materiais trazidos pelos educandos e arquivos elaborados nos mais diversos } \\
\text { softwares utilizados na Informática. }\end{array}$ & & \\
\hline & Desenvolver habilidades de manipulação do software. & Uso técnico & \\
\hline \multirow[t]{2}{*}{ PPP 5} & $\begin{array}{l}\text { Nesse processo o aluno é avaliado sob diferentes aspectos, em diferentes } \\
\text { atividades como produção escrita ou oral, atividades de observação do meio, } \\
\text { aulas em laboratórios (Informática, Biologia, Física e Química), apresentação e } \\
\text { elaboração de trabalhos e projetos, em ação individual e coletiva. }\end{array}$ & \multirow[t]{2}{*}{ Uso pedagógico } & \\
\hline & $\begin{array}{l}0 \text { trabalho desenvolvido no laboratório de Informática será avaliado criteriosa- } \\
\text { mente pelo professor, que irá elaborar as atividades de acordo com o desenvolvi- } \\
\text { mento da turma. }\end{array}$ & & \\
\hline
\end{tabular}

Fonte: elaboração própria.

As discussões em torno das tecnologias digitais que permeiam os projetos políticos-pedagógicos analisados fortalecem a prática e potencializam a organização do trabalho pedagógico da escola. Contudo, é fundamental entender a função que a tecnologia desempenha na escola, bem como os princípios inferidos.

Os princípios analisados e o aprofundamento dos estudos sobre a organização do trabalho pedagógico trazem contribuições relevantes para a compreensão dos limites e das possibilidades da tecnologia digital nos PPP, objetivando a melhoria da qualidade do trabalho educativo.

\section{Discussão}

Na descrição dos dados analisados, retirados dos PPP, pode-se observar que as tecnologias são encontradas em diferentes componentes da estrutura proposta por Padilha (2005). As escolas anunciam a intenção de associar as tecnologias digitais ao documento, no entanto, não apresentam uma organização em sua estrutura que oriente 
para um posicionamento da escola, articulado aos princípios orientadores, na integração das tecnologias digitais.

Ao analisar o cenário voltado à estrutura da gestão das tecnologias digitais nos documentos, percebe-se que as escolas reconhecem a necessidade de integrar o uso dos recursos tecnológicos digitais em sua proposta educativa. Nesse contexto, os laboratórios de informática são citados em todos os PPP como recursos, dentro da estrutura do documento, porém não estabelecem uma relação entre as tecnologias digitais e os demais itens da estrutura do PPP. A interconexão destes elementos permite o delineamento de um caminho a seguir, permitindo a consolidação de uma proposta de educação integrada às tecnologias digitais alinhada aos princípios educativos sugeridos à construção dos PPP.

Ao considerar o PPP como documento estratégico da escola, faz-se necessário considerar ainda elementos como a formação continuada dos professores para o uso das tecnologias digitais, permitindo que essa condição amplie o repertório dos profissionais, além de identificar as potencialidades e lacunas na prática do professor em diferentes contextos e situações de aprendizagem, apoiados no uso das tecnologias digitais. Percebe-se que os PPP não estabelecem uma relação intencional entre o itinerário formativo dos profissionais e o uso das tecnologias digitais em sala de aula, caracterizado como o princípio da valorização dos profissionais da educação.

Entretanto, para que a mudança de cenário ocorra, é imprescindível um olhar estratégico sobre as novas formas de ensinar e de aprender na proposta pedagógica da escola. A condição para que a mudança aconteça de maneira intencional e democrática perpassa o envolvimento dos sujeitos em um processo permanente de reflexão e discussão das demandas da escola, em uma construção coletiva, materializada no PPP.

É relevante reconhecer o esforço que as escolas vêm desenvolvendo no sentido de melhorar a qualidade do ensino e da aprendizagem. O desafio consiste em considerar na construção do PPP a perspectiva dos princípios que orientam as ações da escola frente ao uso da tecnologia digital e da definição de marcos para o estabelecimento do uso pedagógico dessas tecnologias. Considerando o acesso e permanência do aluno na escola, sua autonomia, permitindo ao aluno tomar-se protagonista na construção de seu conhecimento. Todavia, essa relação possibilita ao aluno tornar-se um sujeito pesquisador, reflexivo, construindo um aprendizado significativo à sua vida.

É nessa perspectiva que apresentamos, na Figura 14, a síntese realizada a partir dos dados apresentados nos resultados; emergem os indicadores da relação estabelecida 
com a tecnologia pela escola, e a partir deles foi possível inferir possíveis funções desempenhadas pela escola que necessitariam estar contempladas no Projeto Político Pedagógico para que os princípios elencados por Veiga (1991) se fizessem presentes também na integração das tecnologias ao contexto escolar.

Figura 14: Indicadores da proposta tecnológica da escola no PPP

\begin{tabular}{|c|c|c|c|}
\hline ITEM & FUNÇÕES DESEMPENHADAS & INDICADORES & PRINCÍPIOS INFERIDOS \\
\hline IDENTIFICAÇÃO & $\begin{array}{l}\text { Princípios e concepção da escola } \\
\text { frente a tecnologia digital. }\end{array}$ & $\begin{array}{l}\text { Escola como espaço de inclusão } \\
\text { digital. } \\
\text { A tecnologia propulsora da } \\
\text { produção e disseminação do } \\
\text { conhecimento. }\end{array}$ & $\begin{array}{c}\text { Qualidade de ensino, valorização } \\
\text { do magistério, liberdade e } \\
\text { autonomia. } \\
\text { Gestão democrática e qualidade } \\
\text { de ensino. }\end{array}$ \\
\hline $\begin{array}{l}\text { HISTÓRICO E } \\
\text { JUSTIFICATIVA }\end{array}$ & $\begin{array}{l}\text { Contexto que leva a escola a } \\
\text { delinear os princípios e concepções } \\
\text { de tecnologias adotados. }\end{array}$ & $\begin{array}{l}\text { A tecnologia propulsora da } \\
\text { produção e disseminação do } \\
\text { conhecimento. } \\
\text { Perspectivas da inclusão digital. }\end{array}$ & $\begin{array}{l}\text { Igualdade de condições para } \\
\text { acesso e permanência, gestão } \\
\text { democrática e liberdade e } \\
\text { autonomia. }\end{array}$ \\
\hline $\begin{array}{l}\text { OBJETIVOS GERAIS } \\
\text { E ESPECÍFICOS }\end{array}$ & $\begin{array}{l}\text { Finalidade da tecnologia digital } \\
\text { para a escola. }\end{array}$ & $\begin{array}{l}\text { Uso pedagógico da tecnologia } \\
\text { digital. } \\
\text { Finalidade de inclusão digital. } \\
\text { Letramento digital. } \\
\text { Uso para funções administrativas. }\end{array}$ & $\begin{array}{c}\text { Igualdade de condições para } \\
\text { acesso e permanência e qualidade } \\
\text { de ensino. }\end{array}$ \\
\hline METAS & $\begin{array}{l}\text { Definição de marcos para consecu- } \\
\text { ção das finalidades estabelecidas } \\
\text { para a tecnologia digital no espaço } \\
\text { escolar. }\end{array}$ & $\begin{array}{l}\text { A tecnologia propulsora da } \\
\text { produção e disseminação do } \\
\text { conhecimento. } \\
\text { Uso pedagógico da tecnologia } \\
\text { digital. }\end{array}$ & $\begin{array}{l}\text { Gestão democrática e qualidade } \\
\text { de ensino. } \\
\text { Igualdade de condições para } \\
\text { acesso e permanência e qualidade } \\
\text { de ensino. }\end{array}$ \\
\hline $\begin{array}{l}\text { DESENVOLVIMENTO } \\
\text { METODOLÓGICO }\end{array}$ & $\begin{array}{l}\text { Caminho a ser percorrido para o } \\
\text { alcance dos objetivos e metas } \\
\text { fixadas em relação aos diferentes } \\
\text { indicadores estabelecidos para a } \\
\text { tecnologia. }\end{array}$ & \multirow{4}{*}{$\begin{array}{l}\text { Uso pedagógico da tecnologia } \\
\text { digital. } \\
\text { Alfabetização digital. } \\
\text { Escola como espaço de inclusão } \\
\text { digital. }\end{array}$} & \multirow{4}{*}{$\begin{array}{c}\text { Igualdade de condições para } \\
\text { acesso e permanência e qualidade } \\
\text { de ensino. } \\
\text { Gestão democrática. }\end{array}$} \\
\hline RECURSOS & $\begin{array}{l}\text { Recursos disponíveis na escola para } \\
\text { que desempenhe sua função frente } \\
\text { a tecnologia digital, bem como a } \\
\text { consecução dos objetivos. }\end{array}$ & & \\
\hline CRONOGRAMA & $\begin{array}{l}\text { Prazos para que a escola desempe- } \\
\text { nhe sua função frente a tecnologia } \\
\text { digital, bem como a consecução } \\
\text { dos objetivos. }\end{array}$ & & \\
\hline AVALIAÇÃO & $\begin{array}{l}\text { Medidas para que se garanta a } \\
\text { avaliação constante das propostas } \\
\text { descritas que garantam que a } \\
\text { escola desempenhe sua função } \\
\text { frente a tecnologia digital, bem } \\
\text { como a consecução dos objetivos. }\end{array}$ & & \\
\hline
\end{tabular}

Fonte: elaboração própria. 


\section{Considerações Finais}

Favorecer o uso das tecnologias digitais potencializa a forma de ensinar e aprender, qualificando os processos educativos. Além disso, rompe com o existente e avança para a reorganização das práticas voltadas à pesquisa, inovação e colaboração, marcos decisivos na construção do PPP. Como estratégia, sugerimos que os elementos que constituem o PPP, associados aos princípios apontados por Veiga (1991), dimensionem a trajetória a ser seguida de acordo com a realidade de cada território, suas demandas e necessidades frente aos desafios do contexto social, político, econômico e cultural, afim de estabelecer de forma efetiva as tecnologias digitais como recursos pedagógicos, assegurando unidade, coerência e reflexão nos processos.

Desta forma, articular o uso pedagógico das tecnologias digitais por meio do PPP favorece o acesso e a permanência do educando na escola, potencializando o desenvolvimento das novas práticas, qualifica os profissionais, favorece $o$ desenvolvimento da autonomia do aluno, novas concepções de aprendizagem, proporciona melhores oportunidades e estimula a colaboração entre alunos e docentes.

Faz-se necessário ressaltar que a construção coletiva, a implementação e revisão constante do PPP das escolas necessita estar alinhada às demandas sociais, culturais e tecnológicas de toda a comunidade educativa, respeitando o direito à aprendizagem.

\section{Referências}

ALMEIDA, M. E. B. VALENTE, J. A. Tecnologias e Currículo: trajetórias convergentes ou divergentes? São Paulo: Paulus, 2011.

ALMEIDA, M. E. B; PRADO, M. E. B. B. Apresentação da série integração de tecnologias com as mídias digitais. Boletim do Salto para o Futuro. Brasília: MEC, SEED, 2005.

ALMEIDA, M.E.; ALMEIDA, F.J. Aprender construindo: a informática se transforma com os professores. Coleção Informática para a mudança na Educação. Ministério da Educação e do Desporto - MEC, 1999.

BRASIL. Lei n. 9.394, de 20 de dezembro de 1996. Estabelece as diretrizes e bases da educação nacional. Diário Oficial da União, Brasília, DF, 23 dez. 1996.

FIGUEIREDO, L.K.de A.; MERCADO, L.P.L. Integração de mídias na escola: análise das interações nos materiais do curso Mídias na Educação. Eccos Revista Científica, núm. 25, enero-junio, 2011, pp. 195-234. Universidade Nove de Julho. São Paulo, Brasil. 
GANDIN, D. A Prática do Planejamento Participativo. $7^{\text {a }}$ Edição. Petrópolis. RJ. Vozes, 1999.

GATTI, B. Os agentes escolares e o computador no ensino. São Paulo: FDE/SEE, 1993.

MERCADO, L. P. L. Formação Docente e novas tecnologias. Novas tecnologias na educação: reflexões sobre a prática. Maceió: EDUFAL, 2002. p. 11-28.

PADILHA, P. R. Planejamento dialógico: como construir o PPP da escola. 5. ed. São Paulo: Cortez, 2005.

PIOVESAN, A.; TEMPORINI, E. R. Pesquisa Exploratória: procedimento metodológico para o estudo de fatores humanos no campo da saúde pública. Revista Da Saúde Pública, no. 29, ed. 4, 318-325, 1995.

ROSSARI, M. VOSGERAU, D. S. R. O projeto político-pedagógico e a integração das tecnologias. In: Antunes, R. S. (org.). Tecnologias e mídias digitais na escola contemporânea: questões teóricas e práticas. 1 ed. Curitiba, Appris, 2016. Pág. 37-68.

VASCONCELLOS, C. dos S. Planejamento: Plano de ensino-aprendizagem e Projeto Educativo. São Paulo: Libertad, 1995.

VEIGA, I. P.A. "Escola, currículo e ensino". In: Veiga, I.P.A; Cardoso. M. H. (org.) Escola fundamental: Currículo e ensino. Campinas, Papirus, 1991.

VEIGA, I. P. A. Escola: espaço do projeto político-pedagógico. Campinas: Papirus, 1998.

VEIGA, I. P. da. Projeto político-pedagógico da escola: uma construção coletiva. In: VEIGA, I. P. da (org.). Projeto político-pedagógico da escola: uma construção possível. Campinas: Papirus, 1998.

VOSGERAU, D. S. A. R. Reconception d'une formation à l'intégrationdes TIC à l'enseignementà partir de l' analyse d'une pratique, de sés fonctionnalités et de sés dysfonctions. Thèse présentée à La Faculté dês études Supérieures envue de l'obtentiondu grade de Philosophie Docteur - Option Technologie Educationnelle. Université de Montréal, 2005.

\section{Como referenciar este artigo:}

VOSGERAU, Dilmeire Sant'Anna Ramos.; ROSSARI, Marilusa. Princípios orientadores da integração das tecnologias digitais ao projeto político-pedagógico. Revista Ibero-Americana de Estudos em Educação, Araraquara, v. 12, n. 2, p. 10201036, 2017. Disponível em: <http://dx.doi.org/10.21723/riaee.v12.n2.9051>. E-ISSN: $1982-5587$.

Submetido em: 04/11/2016

Aprovação final em: 03/04/2017 